\title{
Atividades não presenciais mediadas pelas tecnologias: aportes para o ensino de língua espanhola
}

\author{
Rosane Salete Sasset
}

\section{Resumo}

Os cursos presenciais de nível médio começam a inserir um percentual da carga horária em atividades de ensino a distância o que exige de seus profissionais uma contínua busca pelo aperfeiçoamento das práticas pedagógicas. Em um mundo em constante evolução, a necessidade de estar conectado ao outro é uma realidade que pressupóe a integração dos diversos conhecimentos em uma rede de saberes que se constrói a cada click. A partir do ano letivo de 2016, 20\% da carga horária do curso Técnico em Agropecuária Integrado ao Ensino Médio do Instituto Federal de Educação, Ciência e Tecnologia (IFRO) - Campus Colorado do Oeste pode ser ofertada por meio de práticas de ensino a distância. Neste estudo, objetiva-se analisar as contribuiçóes das atividades não presenciais mediadas pelas tecnologias para o ensino de Língua Espanhola. Utilizou-se a pesquisa qualitativa pautando-se no método da pesquisa-ação. As análises mostram que as atividades não presenciais favoreceram um contato maior com o idioma, além de propiciarem interação entre os alunos que se "arriscam" livremente na língua hispânica adquirindo confiança no aprendizado do idioma.

Palavras-chave: tecnologias; ensino; língua espanhola; atividades não presenciais.

\section{Non-present activities mediated by technologies: approaches for Spanish teaching}

\begin{abstract}
The high school classroom courses begin to include a percentage of the course load in distance learning activities, which demands from their professionals a continuous search for the improvement of pedagogical practices. In a constantly evolving world, the necessity to keep connected to the other is a reality that presupposes the integration of diverse knowledge in a network of knowledge that is built with each click. Since 2016, 20\% of the course load of the Agricultural Technician course Integrated to High School at Federal Institute of Education, Science and Technology (IFRO) - Colorado do Oeste Campus can be offered through distance learning practices. This study aims to analyze the contributions of nonpresent activities mediated by technologies for Spanish language teaching. The research used a qualitative approach based on the action research method. The analyzes show that non-present activities provided greater contact with the language, as well as made possible the interaction between students who "risk" freely in the Hispanic language, acquiring confidence in language learning.
\end{abstract}

Keywords: technologies; teaching; Spanish language; non-present activities. 


\section{Introduçáo}

Há poucos anos, discutia-se a chegada da televisão e dos aparelhos de vídeo cassete às salas de aula e a preocupação era quais benefícios e/ou malefícios esses recursos poderiam acarretar para o ensino e aprendizagem dos estudantes. Logo esses "objetos" deram lugar a outros e outros, cada vez com mais recursos e com mais possibilidades para nos conectarmos a distintos objetos e a diferentes pessoas dos mais longínquos lugares deste mundo, que se interliga econômica, política, social e culturalmente em nível global.

Assim, não é de se admirar que muitos dos alunos que frequentam as atuais salas de aula da educação básica sequer conheçam brincadeiras infantis como o jogo da amarelinha, ou tenham participado de algum campeonato de peteca, ou ainda tenham carregado nos bolsos as tão cobiçadas bolinhas de gude. Certamente, em sua maioria, os alunos carregam em suas mochilas, bolsos ou, mais precisamente, em suas mãos, os mais modernos celulares, recheados de "n" aplicativos e que os mantêm conectados aos quatro cantos deste mundo, que gira a uma velocidade impressionante.

Dessa forma, não há como desconsiderar as tecnologias da informação e comunicação (TICs) quando se pensa em atuar em uma sala de aula. Novas modalidades de ensino, práticas pedagógicas e inúmeros recursos vêm contribuindo com o processo de ensino e aprendizagem e exigem que os professores estejam atentos a essas transformaçôes e busquem o constante aperfeiçoamento. De acordo com estudos,

bons professores são as peças-chave na mudança educacional. Os professores têm muito mais liberdade e opçóes do que parece. A educação não evolui com professores mal preparados. Muitos começam a lecionar sem uma formação adequada, principalmente do ponto de vista pedagógico. Conhecem o conteúdo, mas não sabem como gerenciar uma classe, como motivar diferentes alunos, que dinâmicas utilizar para facilitar a aprendizagem, como avaliar o processo ensino-aprendizagem, além das tradicionais provas. (MORAN, 2007, p. 18).

Assim sendo, os profissionais de todas as áreas precisam estar conectados com o mundo. Quando esses profissionais são professores, é praticamente uma obrigação explorar novas alternativas que possibilitem a interligação dos saberes e contribuam para que as conexôes sejam estabelecidas, favorecendo o ensino e a aprendizagem e incentivando o exercício da criatividade e da criticidade táo relevantes na transformaçáo do cidadão. 
Em se tratando do ensino de línguas estrangeiras, as Orientações Curriculares Nacionais para o Ensino Médio - Linguagens, Códigos e suas Tecnologias (BRASIL, 2008) afirmam que, aliado ao ensino do novo idioma devem estar as novas tecnologias que poderão contribuir com a prática pedagógica e beneficiar o processo de ensino e aprendizagem. Também ressaltam que "a função maior de uma língua estrangeira no contexto escolar é contribuir para a formação do cidadão” (BRASIL, 2008, p. 146). Além disso, para aprender um novo idioma, não se pode dissociá-lo de seus valores sociais, culturais, políticos e ideológicos.

Pensando nesses aspectos, vislumbra-se que as atividades não presenciais mediadas pelas TICS, as quais começam a ocupar espaço nos cursos presenciais de nível médio, possam contribuir significativamente para o ensino e aprendizagem da língua estrangeira - espanhol, visto que o aluno poderá utilizar-se dos recursos disponíveis na rede para estabelecer conexóes entre os diversos universos de cada um dos países que possui o idioma como língua oficial.

\section{O Professor e as TICs: Diálogo imprescindível}

Las TIC seguirán cambiando el mundo, y no invertir en ellas es una desventaja. Steve Ballmer

As transformaçóes que marcam a sociedade contemporânea estão intimamente relacionadas ao desenvolvimento da tecnologia. Nos últimos tempos, as relaçóes humanas parecem ter se formado a partir de chips que possibilitam desenvolver conexóes em tempo real, ou não, com ambientes, contextos e épocas inimagináveis há tempos não muito longínquos.

$E$ inquestionável que as TICs chegaram ao universo da escola e adentraram as salas de aula, provocando uma transformação nas tradicionais práticas pedagógicas. Sabe-se que a vinda da tecnologia à escola, desde que explorada em todos os seus recursos, significa inovação na educação, já que proporciona o diálogo entre os mais diversos setores desta e faz com que novos desafios sejam postos a alunos e professores a fim de que se obtenha êxito no processo de ensino e aprendizagem.

Nesse sentido, é preciso estar atento ao que destacam Brandáo e Teixeira (2002, p. 4), quando afirmam que "no mundo transformado pela tec- 
nologia mais do que nunca a educação deve estar apoiada na busca de alunos e professores inventivos e criativos capazes de preconizar uma sociedade melhor". É a partir disso que o diálogo entre as TICs e a prática docente se torna imprescindível para que professores e alunos possam estabelecer a interaçáo necessária, a fim de atuar de forma crítica e independente na sociedade. É preciso que os professores explorem as vantagens que a tecnologia oferece e compartilhem com os alunos todos os benefícios, para torná-los críticos e criativos, agindo como cidadãos participativos das transformaçôes sociais, culturais e políticas, bem como da busca por novos entendimentos.

As TICs, ao serem utilizadas no ambiente educacional, podem promover a autonomia do aluno, pois possibilitam o desenvolvimento de estratégias de busca em relação aos temas que são propostos, bem como estimulam que se estabeleçam critérios para escolher determinadas fontes de informação, por exemplo. Cabe ao professor colaborar com a produção dessa autonomia, criando espaços colaborativos mediados pela tecnologia para que os estudantes exercitem sua criticidade e saibam o verdadeiro sentido que tais açóes proporcionam à sua formação cidadã.

Dessa forma, é oportuno considerar as afirmaçóes feitas por Zulian e Freitas que, ao se referirem às TICs nos ambientes escolares, afiançam que os ambientes de aprendizagem

baseados nas tecnologias da informação e da comunicação, [...] e de outros recursos e linguagens digitais, proporcionam atividades com propósitos educacionais, interessantes e desafiadoras, favorecendo a construçáo do conhecimento, no qual o aluno busca, explora, questiona, tem curiosidade, procura e propóe soluçóes. (ZULIAN; FREITAS, 2001, p. 2).

Diante disso, entende-se que a inserção das TICs nas práticas pedagógicas é indispensável, entretanto convém analisar como está sendo a ação docente nas escolas, em razão de que deve ser respeitada a heterogeneidade que conforma a sala de aula e as múltiplas inteligências, além das inúmeras necessidades que são impostas pela sociedade, aos cidadãos, e que muitas vezes é a escola que precisa dar conta dos meios para atingi-las. Quanto a isso, afirma Moran:

Escolas não conectadas são escolas incompletas (mesmo quando didaticamente avançadas). Alunos sem acesso contínuo às redes digitais estáo excluídos de uma parte importante da aprendizagem atual: do 
acesso à informação variada disponível on-line, da pesquisa rápida em bases de dados, bibliotecas digitais, portais educacionais; da participação em comunidades de interesse, nos debates e publicaçóes on-line, enfim, da variada oferta de serviços digitais. (MORAN, 2007, p. 9-10).

Entende-se que as TICs, em ambientes escolares, são importantes elos entre a educação e a sociedade complexa, da qual professores e alunos também fazem parte, que pressupóe a utilização da linguagem e dos recursos digitais, a fim de obter informaçóes que contribuem significativamente para a transformaçáo do conhecimento. Acredita-se ser de fundamental importância, nas salas de aula atuais, a criação de ambientes de aprendizagem interdisciplinares, colaborativos, dinâmicos, significativos e que estabeleçam as conexôes necessárias para a integração das ciências.

Nesse sentido, as TICs oportunizam o acesso à pesquisa, às explicações diversas e permitem que os estudantes possam ser agentes transformadores de sua própria aprendizagem. Atividades desenvolvidas a partir de recursos disponíveis na "grande rede", por exemplo, oferecem mais opçóes para que alunos e professores encontrem pessoas que compartilhem dos mesmos interesses e iniciem uma rede de interconexão de sabedorias que contribuirá significativamente na formação de uma sociedade mais democrática e humana. É nesse cenário que as atividades não presenciais, mediadas pelas TICs, começam a ocupar terreno nos cursos presenciais de nível médio.

\subsection{As atividades não presenciais compondo a carga horária de cursos presenciais}

"É impossível haver progresso sem mudança, e quem não consegue mudar a si mesmo não muda coisa alguma."

Bernard Shaw

As mudanças sempre estiveram presentes nas ações humanas, conforme expressa o pensamento de Bernard Shaw, e foram as responsáveis pelos grandes avanços em todos os setores da sociedade. Quando se trata de educação, é inegável que, com o advento das novas tecnologias da informação e comunicação, as mudanças precisam ocorrer. Não há como ficar alheio a tantos avanços. Assim sendo, a escola e seus professores começam a inserir em suas práticas, as atividades não presenciais mediadas pelas TICs, 
acreditando que o diálogo que se estabelece entre a tecnologia e a realidade educacional pode contribuir para que o ensino ocorra de modo ativo, personalizado e abrangente.

Essa nova modalidade de aprendizagem híbrida que começa a ganhar terreno no campo educacional pode ser chamada de blended learning (b-learning) e mescla, em suas atividades pedagógicas, práticas características do ensino presencial com outras mais específicas do ensino a distância. Ao utilizar as TICs, as práticas pedagógicas fundamentadas no blended learning agregam diversas ferramentas eletrônicas que possibilitam atender a distintos perfis de estudantes, dado que

O Blended Learning apresenta novas possibilidades educacionais, que proveem não apenas a aplicação de recursos para gerenciamento de conteúdo e processos de ensino-aprendizagem em educação a distância, mas também o uso das TIC, na perspectiva de agregar valor a processos de educação presencial. (ANJOS, 2012, p. 12).

O fenômeno da convergência entre as atividades virtuais e presenciais vem ocupando um espaço significativo nas práticas pedagógicas e em virtude disso tem sido tema de muitas pesquisas entre os educadores. $\mathrm{O}$ avanço e ampliação do uso das TICs em cursos presenciais têm permitido um diálogo maior entre educadores e também entre estudantes. Manter a atenção dos alunos em um ambiente virtual não é tarefa fácil. Assim, o blended learning é visto como um campo fértil para que sejam aprimoradas estratégias e pensadas técnicas inovadoras que permitam acompanhar como está ocorrendo o processo de ensino e de aprendizagem, além de incentivar práticas colaborativas, que motivem e envolvam os sujeitos participantes de tal processo. A seguir, é possível verificar a esquematização da evolução do blended learning, modelo que deve pautar a Educação do Futuro (TORI, 2010).

Passado: a aprendizagem presencial (AP) é predominante, sistemas inteiramente afastados dos avanços nas tecnologias interativas, aprendizagem virtual (AV), conforme Figura 1. 
Fig. 1 - Processo de Aprendizagem do Passado.

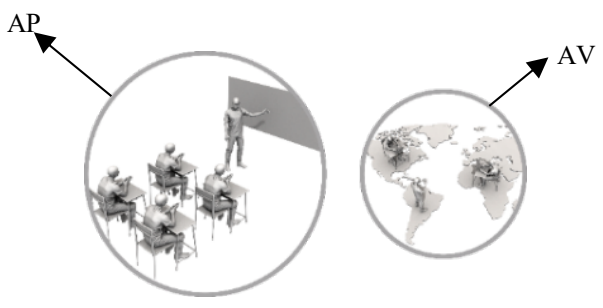

Fonte: Adaptado de Tori (2010)

Presente: os sistemas de aprendizagem virtual ocupam mais espaços, ocorre a aproximação entre aprendizagem presencial (AP) e aprendizagem virtual (AV), e percebe-se o blended learning (BL) em progresso, conforme Figura 2.

Fig. 2 - Processo de Aprendizagem do Presente.

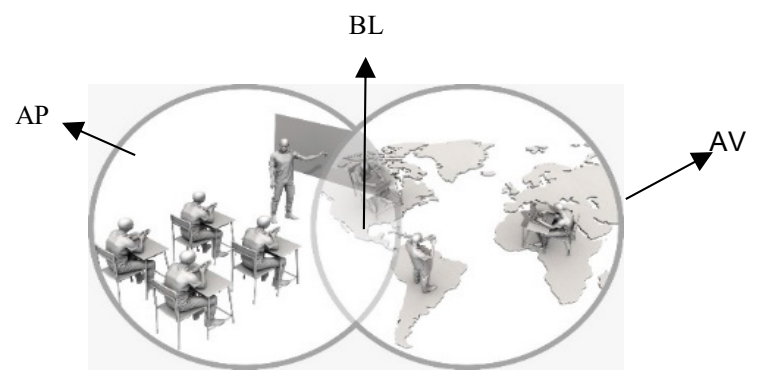

Fonte: Adaptado de Tori (2010).

Futuro: nota-se a superioridade do blended learning, e a entrada de novas tecnologias interativas provoca acréscimo na percepção de presença e imersão, conforme Figura 3. 
Fig. 3 - Processo de Aprendizagem do Futuro.

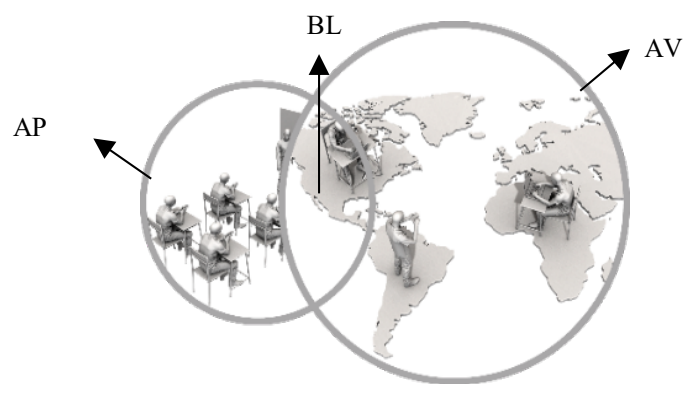

Fonte: Adaptado de Tori (2010).

Diante disso, é imprescindível considerar os avanços das atividades a distância e a busca por modelos que apresentem uma maior flexibilidade entre a educação presencial e a educação a distância, pois

com as tecnologias cada vez mais rápidas e integradas, o conceito de presença e distância se altera profundamente e as formas de ensinar e aprender também. Estamos caminhando para uma aproximação sem precedentes entre os cursos presenciais (cada vez mais semipresenciais) e os a distância. Os presenciais terâo disciplinas parcialmente a distância e outras totalmente a distância. E os mesmos professores que estáo no presencial-virtual começam a atuar também na educação a distância. Teremos inúmeras possibilidades de aprendizagem que combinaráo o melhor do presencial (quando possível) com as dificuldades do virtual. (MORAN, 2004, p. 7).

Considerando toda essa nova configuração que se revela em termos de novas perspectivas para a educação, o Conselho Nacional de Educação, através da Resolução CNE/CEB no 06/2012, que define as Diretrizes Curriculares Nacionais para a Educação Profissional Técnica de Nível Médio, quando se trata da carga horária dos cursos, se posiciona a respeito:

Art. 26 [...] Parágrafo único. Respeitados os mínimos previstos de duração e carga horária total, o plano de curso técnico de nível médio pode prever atividades náo presenciais, até $20 \%$ (vinte por cento) da carga horária diária do curso, desde que haja suporte tecnológico e seja garantido o atendimento por docentes e tutores. (BRASIL, 2012b). 
A fim de dirimir qualquer dúvida de interpretação literal do que está expresso no artigo citado, importa analisar também o estabelecido no Parecer CNE/CEB no 11/2012, norteador da referida Resolução, e que assim expressa $\mathrm{O}$ assunto:

É possível, por outro lado, planejar o curso com parte não presencial, desde que respeitados os mínimos previstos de duração e carga horária total. Assim, o curso pode incluir atividades náo presenciais, até $20 \%$ (vinte por cento) da carga horária diária ou de cada tempo de organização curricular, desde que haja suporte tecnológico e seja garantido o necessário atendimento por docentes e tutores. (BRASIL, 2012a, p. 41).

Assim sendo, cabe atender o disposto na legislação, quando da elaboração dos projetos pedagógicos dos cursos técnicos de nível médio e presenciais. No caso de a organização curricular contemplar o modelo blended learning, a instituição deverá disponibilizar aos discentes todo o suporte tecnológico, bem como contar com o atendimento de professores e tutores. Estes precisarão receber a capacitação necessária para exercer as novas funçóes a eles atribuídas, a fim de que ocorra a interação mediada pelas TICs e se produzam efeitos favoráveis no processo de ensino e aprendizagem.

\subsection{A aprendizagem de línguas mediada pelos recursos disponíveis na rede}

"As tecnologias de informação e comunicação não são mais uma ferramenta didática ao serviço dos professores e alunos... elas são e estáo no mundo onde crescem os jovens que ensinamos..." Jordi Adell

São essas tecnologias de informação e comunicação a que se refere Jordi Adell (1997) que adentraram as salas de aula e são parte delas. Não há como ignorá-las, porque é por meio dessas que nos conectamos ao mundo cada dia mais interligado.

Nesse contexto, o ensino de língua estrangeira deve ser pensado ponderando a globalização emergente que se apresenta em todos os segmentos da sociedade, bem como o avanço das TICs. Também é bastante significativo levar em conta o perfil dos jovens que frequentam as atuais salas de 
aula. Em sua maioria, esses jovens nasceram em uma época de expansão das tecnologias digitais e estão cercados de smartphones, tablets, dentre tantos outros equipamentos eletrônicos. Para nossos alunos, o ato de folhear um livro significa táo somente deslizar o dedo sobre uma tela. Sendo assim, o ensino de língua estrangeira, mediado pelas TICs, poderá cumprir relevante papel de restabelecer as conexóes entre as diversas ciências, permitindo o desenvolvimento de uma consciência social que esteja apta para pensar e ver o mundo sob outra perspectiva. De acordo com Tori (2010, p. 28), "aos poucos os educadores e os próprios alunos estão descobrindo que os recursos virtuais podem ser um excelente suporte às atividades presenciais".

Além disso, há que se levar em consideração os apontamentos de Trujillo (2007), em relação ao ensino de língua e o uso das TICs. Vejamos:

Las nuevas tendencias sociales presentes en la escuela han enriquecido el panorama de la enseñanza de lenguas en el contexto escolar. [...] Los pilares de este marco de actuación didáctica son la enseñanza por competencias y tareas, el currículum integrado, el aprendizaje cooperativo y el uso de las TIC en el aula." (TRUJILLO, 2007, p. 71)

Assim, pode-se dizer que as TICs mudaram a concepção de ensino e aprendizagem, principalmente, para aqueles que nasceram em uma sociedade tecnológica. Utilizar os recursos que estão disponíveis na internet, nas práticas pedagógicas, contribui para a criação de um ambiente facilitador da aprendizagem de línguas estrangeiras.

Sabe-se que o domínio de idiomas é vital na sociedade atual e o estudante precisa estar consciente do quão importante é aprender uma nova língua. Cabe ao professor oferecer as mais diversas ferramentas que possibilitem a aquisição dessa língua e proporcionem a efetiva aprendizagem. Muitos são os recursos que podem ser utilizados, pois aprender um novo idioma não se restringe apenas aos aspectos linguísticos. Uma língua é o resultado de um conjunto de fatores que compóem a cultura, a identidade de um povo. As atividades não presenciais mediadas pelas TICs podem trazer grandes contribuiçôes em relação ao acesso à cultura do outro, permitindo ao aluno, quando se dispuser a aprender um novo idioma, ultrapassar as fronteiras dos aspectos linguísticos desse vernáculo.

Dessa forma, as TICs devem ser vistas como vieses importantes na aprendizagem de línguas e utilizadas como estratégias facilitadoras para eliminar barreiras, tempo e distância, contribuindo para o intercâmbio cul- 
tural. Além de a língua constituir um instrumento de comunicação, ela é também um agente de transformação social.

\section{Percurso metodológico}

O presente estudo tem como objetivo analisar as contribuições das atividades não presenciais mediadas pelas TICs para o ensino e aprendizagem de Língua Espanhola. Para isso, o percurso metodológico seguido considerou os aspectos qualitativos e pautou-se no método da pesquisa-ação. A pesquisa-ação é fruto da necessidade de superar o vazio que há entre teoria e prática. Dentre as características desse tipo de pesquisa se encontra o fato de que é por meio dela que se procura intervir na prática de modo inovador já no decorrer do próprio processo de pesquisa.

A esse respeito, Thiollent (2011, p. 14) afirma que

A pesquisa-ação é um tipo de pesquisa social com base empírica que é concebida e realizada em estreita associação com uma ação ou com a resolução de um problema coletivo e no qual os pesquisadores e os representativos da situação ou do problema estáo envolvidos de modo cooperativo ou participativo.

Nesse sentido, quando da realização de uma pesquisa-ação é importante atentar-se para o fato de que o pesquisador não está agindo sobre outros, mas está agindo com os outros (BARBIER, 2002).

Como primeiro passo, analisou-se a ementa e o plano de ensino da disciplina Língua Espanhola, do curso Técnico em Agropecuária Integrado ao Ensino Médio, do IFRO Campus Colorado do Oeste, a fim de verificar que saberes poderiam ser desenvolvidos por meio de atividades não presencias e quais estratégias caberiam para que o trabalho fosse relevante, além de contribuir com o ensino e aprendizagem do idioma hispânico.

Passada essa etapa, a pesquisa foi iniciada com os 30 (trinta) alunos, de uma turma do terceiro ano do curso Técnico em Agropecuária Integrado ao Ensino Médio. A escolha da turma ocorreu aleatoriamente, entretanto o ano (terceiro) foi pelo fato de que os alunos já estão familiarizados com o idioma, pois no segundo ano começam os primeiros contatos com a aprendizagem da língua espanhola. Fez-se, primeiro, o levantamento quanto ao acesso dos alunos aos computadores disponíveis na escola e nas residências dos envolvidos na pesquisa. Além disso, foi verificado se todos os alunos 
possuíam conta de e-mail ativa e que fosse compatível para acessar a ferramenta do Google Docs que foi escolhida para a realização da atividade, em função da facilidade de manuseio dos recursos nela disponíveis.

Iniciou-se o trabalho propriamente dito e todos os alunos, em duplas, realizaram uma investigação, utilizando livremente sites, em língua espanhola, de universidades e/ou centros de pesquisas sobre a fruticultura em diferentes países de língua hispânica, localizados no continente americano. A escolha da temática fruticultura se deu em função de que esse é um dos assuntos abordados na disciplina técnica de Produção Vegetal e que compóe o currículo do terceiro ano, além de permitir trabalhar os conteúdos de língua espanhola, que ademais dos aspectos linguísticos, prevê aspectos culturais dos países hispânicos. A tarefa realizada foi a escrita de dois parágrafos sobre a temática que compartilharam no Google Docs, para se familiarizarem com o recurso e com a nova estratégia de ensino e aprendizagem. De posse dessas referências, os alunos foram divididos em três grupos e convidados a elaborarem um texto coerente e coeso, em língua espanhola, sobre a fruticultura nos países hispano-americanos. Para isso, o documento foi disponibilizado por meio do Google Docs e, em seus respectivos grupos, os alunos começaram a dar suas contribuiçóes, aprendendo a trabalhar colaborativamente.

Concluída essa fase, partiu-se para a próxima etapa. Como já haviam tido o primeiro contato com os recursos do Google Docs, novas atividades foram propostas e nova configuração nas equipes foi estabelecida. Os alunos formaram livremente seis equipes com cinco componentes cada uma. Em seguida, por sorteio, cada equipe recebeu o nome de um fruto que apresenta produção significativa em países hispano-americanos. Os nomes dos frutos sorteados, com seus respectivos nomes científicos, estão em espanhol e são os seguintes: café (Coffea sp.), cacao (Theobroma cacao), acerola (Malpighia glabra), banana (Musa ssp.), piña (Ananascomosus) e maracuyá (Passiflora edulis).

As equipes foram comunicadas de que os dados a respeito de cada fruto seriam compartilhados no Google Drive, ao qual o Google Docs está integrado, a fim de que as investigaçôes sobre a temática prosseguissem. Foi disponibilizado, juntamente com o material de pesquisa, um roteiro que auxiliou a elaboração do trabalho final de cada equipe.

Antes de disponibilizar o material às equipes, o docente de língua espanhola realizou uma intensa pesquisa sobre a temática, além de dialogar com o docente da disciplina de Produção Vegetal, a fim de que a seleção de artigos, revistas, links que direcionavam a textos, palestras, vídeos e demais 
recursos que seriam disponibilizados, relacionados a cada um dos frutos a serem pesquisados, fossem relevantes tanto para o aprendizado da língua espanhola quanto da disciplina técnica.

As pesquisas foram direcionadas ao material prévio disponibilizado, entretanto nada impedia que os alunos utilizassem outros materiais disponíveis na rede. Pelo fato de os alunos não terem o hábito de utilizar o Google Drive e Google Docs, o docente optou por dar esse direcionamento, a fim de verificar como se daria a desenvoltura dos alunos diante da nova estratégia de aprendizagem que se apresentava e também pensando em otimizar o tempo disponível para tal atividade.

Como trabalho final, nessa etapa, os alunos produziram um pôster que continha informes relacionados à origem da planta e do fruto, nome científico, as condiçóes ideais para plantio, principais produtores mundiais do fruto, valores nutricionais e utilização do fruto na alimentação humana, além dos aspectos culturais relacionados ao fruto (lendas, crenças, mitos, culinária). Salienta-se que o docente estipulou, em comum acordo com os alunos de cada equipe, um horário em que estaria disponível para orientá-los e esclarecer dúvidas, por meio do Google Docs.

Após a efetivação das atividades relatadas, cada equipe, agora em aulas presenciais, expôs o trabalho concretizado para os demais colegas da turma. Foi um momento em que puderam compartilhar os conhecimentos adquiridos, contribuir com a transformação das experiências de cada um dos alunos, vivenciar aspectos culturais e sociais de diferentes países hispano-americanos, exercitar a criticidade e mostrar os resultados de um trabalho colaborativo, além da possibilidade de se expressar por meio da escrita e da oralidade em língua espanhola.

Após a conclusão de todas as atividades, os alunos responderam a um questionário impresso sobre as contribuiçóes da utilização da ferramenta do Google Docs para a aprendizagem da língua espanhola, além da realização de uma avaliação das atividades utilizando a técnica do grupo focal. 


\section{Apresentação e discussão dos dados}

\subsection{Apresentação dos dados coletados}

As figuras de 4 a 10 retratam os dados obtidos junto aos trinta e cinco alunos de uma turma de terceiro ano do curso Técnico em Agropecuária Integrado ao Ensino Médio, modalidade presencial, os quais participaram de atividades não presenciais, na disciplina de língua espanhola, mediadas pela ferramenta Google Docs.

Fig. 4 - Acesso a computador com internet

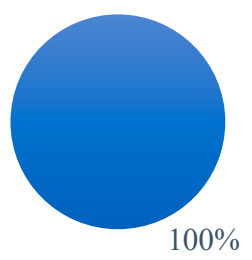

Fonte: Elaboração da autora

\section{Sim $\square$ Não}

$\mathrm{Na}$ figura 4, percebe-se que todos os alunos possuem acesso ao computador com internet. Essa é uma informação importante, pois há um espaço bastante profícuo para o desenvolvimento de atividades mediadas pelas TIC. Estratégias de ensino e aprendizagem voltadas para açōes colaborativas mostram-se favoráveis nesse contexto, como é o caso do uso da ferramenta Google Docs.

Fig. 5 - Frequência com que utiliza a internet fora da sala de aula e/ou escola

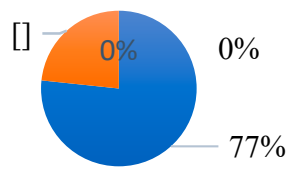

Diariamente Semanalmente

Raramente

Fonte: Elaboração da autora 
A figura 5 mostra que o acesso à internet ocorre diariamente para $77 \%$ dos alunos. Somente $23 \%$ desses alunos têm acesso à internet semanalmente. Os dados demonstram que é bastante favorável o uso das ferramentas disponíveis na internet para a prática de atividades náo presenciais.

Fig 6 - Fins de utilização da internet

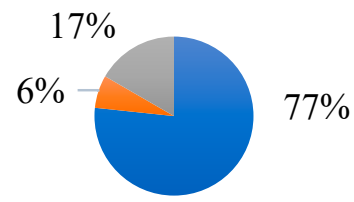

\section{— Pesquisas / Estudos — Uso Pessoal— Diversão}

Fonte: Elaboração da autora

De acordo com os dados apresentados, $77 \%$ dos alunos fazem uso $\mathrm{da}$ internet para realizar pesquisas e/ou estudos relacionados às atividades escolares diárias. Um percentual de $17 \%$ dos alunos busca algum tipo de diversão na rede e $6 \%$ deles para uso pessoal.

Fig. 7 - Conhecimento sobre a ferramenta Google Docs

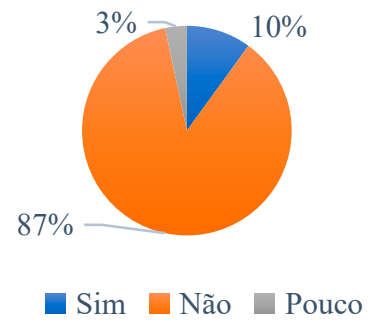

Fonte: Elaboração da autora

Quanto a terem conhecimento sobre a ferramenta Google Docs, $87 \%$ afirmaram não possuírem conhecimento, 10\% relataram saber utilizá-la e 3\% disseram saber muito pouco a respeito da ferramenta. Os alunos que têm conhecimento sobre o Google Docs aprenderam durante as aulas da disciplina de Informática, quando eram alunos do primeiro ano. 
Fig. 8 - Google Docs contribuiu para a aprendizagem de Língua Espanhola

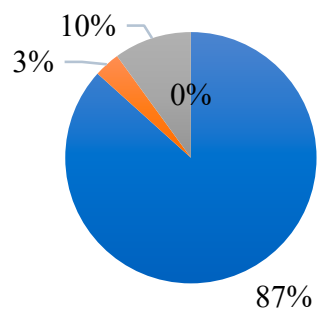

Sim $\square$ Não $\square$ Pouco

Fonte: Elaboração da autora

Em relação à contribuição da ferramenta Google Docs para a aprendizagem da língua espanhola, 87\% dos alunos afirmaram que houve contribuição. Já para $10 \%$, a utilização da ferramenta trouxe poucas contribuiçôes para a aprendizagem e 3\% afirmaram que não foi favorável o uso do Google Docs para a aprendizagem da disciplina de língua espanhola.

Fig. 9 - Dificuldades encontradas para usar o Google Docs

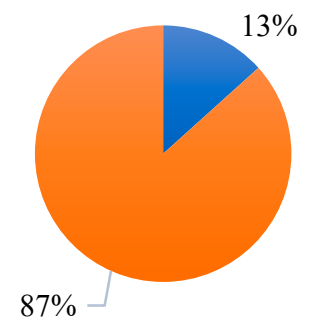

- Sim $\square$ Não

Fonte: Elaboração da autora

Em relação às dificuldades encontradas na utilização do Google Docs, $87 \%$ dos alunos afirmaram não ter se deparado com problemas. Entretanto, $13 \%$ disseram ter encontrado dificuldades para usar a ferramenta. 
Fig. 10 - Proporcionou integração e aprendizagem colaborativa

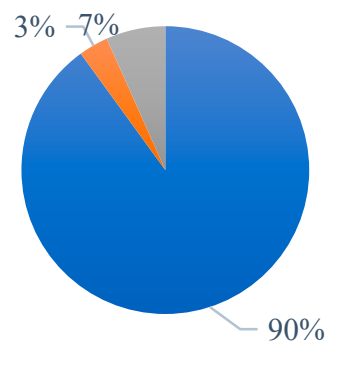

Sim $\square$ Não $\square$ Pouco

Fonte: Elaboração da autora

Quanto à utilização da ferramenta Google Docs ter proporcionado integração entre os alunos e oportunizado a aprendizagem colaborativa, $90 \%$ dos estudantes afirmaram que o uso do recurso foi positivo; para $7 \%$, os resultados obtidos são poucos e $3 \%$ disseram não ter havido resultados favoráveis em decorrência da utilização do Google Docs.

Diante dos resultados apresentados, é possível constatar que a ferramenta Google Docs, na modalidade de aprendizagem híbrida, representa um recurso em potencial a ser explorado pelos docentes e discentes dos diversos níveis de ensino.

\subsection{Discussão e análise dos dados}

Diante dos resultados apresentados, constata-se que o acesso às TICs está consolidado entre os alunos. Nota-se que o acesso diário à internet mostra-se favorável ao desenvolvimento de atividades que utilizam o blended learning, pois a grande maioria dos alunos envolvidos no trabalho afirma que a utilização da internet é feita com fins de pesquisas e estudos, o que demonstra que as TICs são fortes aliadas das práticas pedagógicas dos docentes que procuram tornar suas aulas dinâmicas, criativas, além de incentivarem a autonomia intelectual do aluno.

A utilização da ferramenta Google Docs, mesmo para alunos que não possuíam conhecimento sobre seu uso, foi bastante significativa. A integração e o exercício do diálogo oportunizaram, além do aprendizado da língua espanhola, o trabalho em equipe. Mesmo não dominando a ferramenta 
Google Docs, os alunos não se intimidaram, pois representam uma geração que está crescendo cercada por recursos digitais.

A estratégia pedagógica mediada pelos recursos disponíveis no Google Docs trouxe contribuiçóes significativas para o aprendizado de língua espanhola, pois o contato direto com textos de diferentes gêneros colocou os alunos mais próximos da realidade do falante hispânico e de toda a sua diversidade história, econômica, social e cultural. Aprender o idioma espanhol proporcionou acesso a novas referências e promoveu a interdisciplinaridade com a disciplina técnica de produção vegetal, por isso náo deixa de ser uma atividade integradora e, em consequência, possibilitou a aquisição de fundamentos relacionados às questóes agrícolas, em especial à produção de frutas, dos países hispano-americanos.

As atividades apresentadas por meio do blended learning despertaram o interesse dos alunos para aspectos do idioma que até então não haviam considerado. Aspectos linguísticos foram significativos para o aprendizado, entretanto nada se compara à quantidade de dados acerca dos aspectos culturais que foram absorvidos e incorporados às referências que cada um dos alunos já havia assimilado. A relevância que a cultura de um povo tem sobre sua identidade não se aprende em regras gramaticais, se aprende na vivência com o outro, seja presencial ou virtualmente.

Mais do que qualquer conteúdo, o trabalho colaborativo proporcionou integração entre os alunos, que precisaram aprender a discutir ideias e trabalhar em equipe para que pudessem obter êxito no trabalho em que estavam envolvidos. As conexóes de sapiências que foram construídas nesse convívio são de fundamental importância para despertar a consciência de que cada um pode ser agente transformador de suas próprias práticas e da sociedade.

\section{Consideraçóes Finais}

Mudanças são necessárias, entretanto sempre exigem um grande esforço de todos os envolvidos para que sejam rompidos paradigmas que estão amalgamados nas práticas de muitos docentes. Estratégias pedagógicas ancoradas no blended learning assinalam o caminho a seguir na constituição de uma educação mais abrangente e colaborativa, capaz de integrar diversos setores e ciências que estão envolvidos na transformação da sociedade. 
A proposta desenvolvida, fazendo uso dos recursos disponíveis no Google Docs, permitiu a consolidação de trabalho em equipe fortalecido pela criatividade, interação e cumplicidade entre aluno/aluno e aluno/professor, sendo mediado pelas TICs. O aluno se viu como produtor e transformador do próprio conhecimento, transitando com desenvoltura pela sala de aula presencial e virtual.

\section{Referências}

ADELL, Jordi. Tendencias en educación en la sociedad de las tecnologías de la información. EDUTEC, Revista Electrónica de Tecnología Educativa, no 7 , nov.1997. Disponível em: http://nti.uji.es/docs/nti/Jordi_Adell_EDUTEC. html. Acesso em: 10 jul. 2019.

ANJOS, AlexandreMartins dos. Tecnologias da informação edacomunicação, aprendizado eletrônico e ambientes virtuais de aprendizagem. In.: MACIEL, Cristiano (org.). Ambientes Virtuais de Aprendizagem. Cuiabá: EDUFMT, 2012.

BALLMER, Steve. Consejo de Delegado de Microsoft Corp. CEO, 2004.

BARBIER, R. A pesquisa-ação. Brasília: Líber Livro, 2002.

BRANDÁO, Edemilson; TEIXEIRA, Adriano Canabarro. Software Educacional o Complexo Dominio dos Multimeios.Passo Fundo: Material didático, Universidade de Passo Fundo, 2002.

. Orientaçóes Curriculares para o Ensino Médio:Linguagens, Códigos e suasTecnologias. Brasília, Secretaria de EducaçãoBásica, 2008.

- Ministério da Educação. Conselho Nacional de Educação. Câmara de Educação Básica.Parecer CNE/CEB no 11/2012. Brasília, 2012a. Disponível em: http://portal.mec.gov.br/index.php?option=com_ docman \&view=download \&alias=10804-pceb011-12-pdf\&category_ slug=maio-2012-pdf\&Itemid=30192. Acesso em: 10 jul. 2019.

- Ministério da Educação. Conselho Nacional de Educação. Câmara de Educação Básica. Resolução CNE/CEB no 6/2012. Brasília, 2012b. Disponível em: 
http://portal.mec.gov.br/index.php?option=com_docman\&view= download\&alias=11663-rceb006-12-pdf\&category_slug=setembro-2012pdf\&Itemid=30192. Acesso em: 10 jul. 2019.

MORAN, José Manuel. A Educação que desejamos:novos desafios e como chegar lá. 2.ed. Campinas, SP: Papirus Editora, 2007.

THIOLLENT, M. Metodologia da Pesquisa-ação.18. ed., São Paulo: Cortez Autores Associados, 2011.

SHAW, Bernard. In: ANDRADE, João. Máximas para o trabalho e sua vida pessoal. País do Futuro. Edição Digital, 2013.

TORI, Romero. Educação sem distância: as tecnologias interativas na redução de distâncias em ensino e aprendizagem. São Paulo: Editora Senac São Paulo, 2010.

TRUJILLO, Fernando. Enseñar nuevas lenguas en la escuela. Revista de Educación. 343. Gobierno de España, 2007. Disponível em: https:// fernandotrujillo.es/ensenar-nuevas-lenguas-en-la-escuela-11-12-le-nl/. Acesso em: 15 jul. 2019.

ZULIAN, Margaret Simone; FREITAS, Soraia Napoleão. Formação de professores na educação inclusiva: aprendendo a viver, criar, pensar e ensinar de outro modo. Revista do Centro de Educação, Santa Maria, v. 2, n. 18, 2001.

Recebido em: 07 set. 2019.

Aceito em: 12 nov. 2019. 